\title{
Research on the Integration of Environmental Protection Concept into College Ideological and Political Education
}

\author{
Wenjia $\mathrm{Hao}^{1 *}$ \\ College of Environmental Science and Engineering, Guilin University of Technology, Guilin, Guangxi
}

\begin{abstract}
The integration of environmental protection with college ideological and political education is a kind of new exploration in university sustainable education. The spread of sustainability and ecological awareness is fit for modern educational goal. Since university students have not realized the emergency and significance of sustainability and environmental protection, the integration of these concepts into ideological and political education provides a channel for them to understand and practice. This paper will investigate the possible methods for universities and colleges to integrate environmental protection concept into ideological and political education.
\end{abstract}

\section{INTRODUCTION}

With the high and fast development of industrial civilization, people have to face the problems of energy resources exhausted and air pollution. The best way to solve these problems is to combine the nature world with economic development in the future. To fulfill this goal, we must constantly improve the awareness of environmental protection supporting by scientific and technological methods. Environmental protection education is becoming popular to spread sense of responsibility and ecological responsibility. Therefore, the education of university needs to impart the knowledge of ecological environment protection and foster the ability of ecological responsibility, which in this way could make the society move towards the ecological civilization society [1].

Political education in university cultivates students' opinion of values, world view and traditional morality. The first aim of political education is to deliver the morality and quality to the college students, which could promote the formation of correct mindset, and lead the correct value orientation, for contributions to the society positively.

\section{The guidance of improving the concept of environmental protection education}

\subsection{Sustainable development education}

There is an increasing discussion on social, economic and environmental problems because of the global economic structure changing, such as unequal distribution of resources, population growth, climate change, energy supply, ecosystem, food security and environmental toxins Sustainable development education is basically the education of values, and the core content focuses on contemporary and future generations, including differences and diversity, environment and resources on the planet.

The concept of sustainable development education is to examine the reform and development of education from the perspective of sustainable development strategy, and promote the theory and practice of education development to a new boundary. Sustainable development education also focuses on high-quality education [2]. 


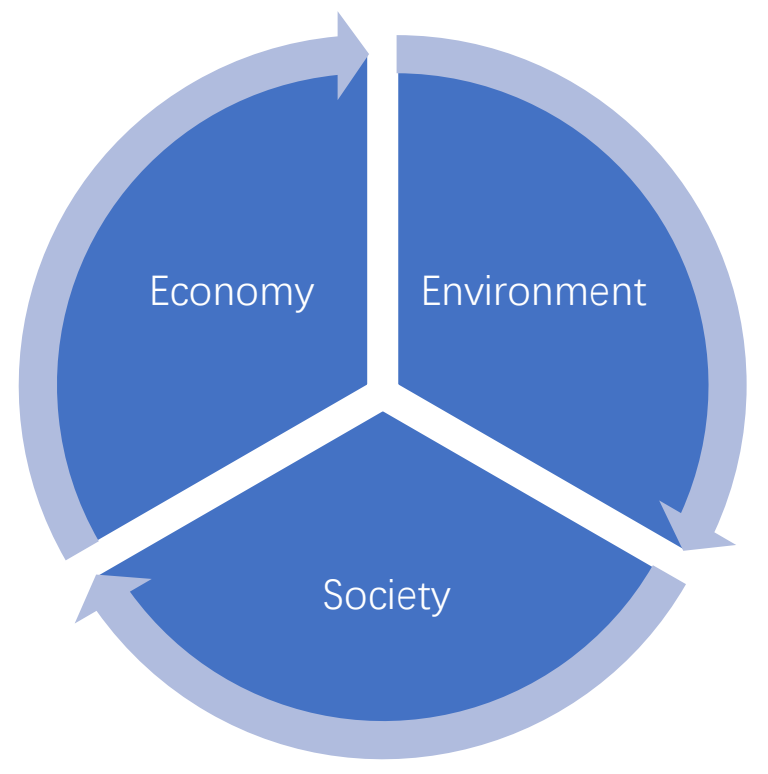

Figure 1 The basic concept of sustainable development

\subsection{Ecological consciousness education}

Ecological consciousness education is a culture of harmonious coexistence and coordinated development between human and nature. It is an important carrier of cultural to integrate the achievements of modern civilization and the spirit of the times, for promoting the harmonious coexistence of man and nature. Ecological consciousness and culture are indispensable force to construct ecological civilization. Therefore, to cultivate citizens' ecological consciousness, we need to actively promote ecological culture education [2].

The main purpose of ecological consciousness education is to assist people establishing correct ecological values, and guide people to fully understand the important value of environment for human survival and development. It can also solve the existing problems of ecological environment in China. Besides, ecological consciousness education can help to develop ecological civilization quality and promote the long-term development of ecological civilization construction.

\section{The importance of environmental protection concept in Ideological and Political Education}

In the new era of education construction, the concept of environmental protection should be integrated in the way of moral restraint and code of conduct, in order to effectively increase college students' ideological and moral consciousness. College students in the new era need to posse the latest idea and basic quality of environmental protection and ecological civilization, and gradually become the promoter and practitioner. It is of great significance to strengthen the education of environmental protection concept, and standardize the behavior of college students who can better participate in the construction of ecological civilization for the society [3]. First, the awareness of environmental protection for college students is not strong as a whole. The survey data showed that the awareness score of college for undergraduate, master and above groups is more than 1.5 points greater than other groups on average, and they have mastered rich knowledge of ecological civilization, but the practice score is even lower than that of primary school and below groups. 


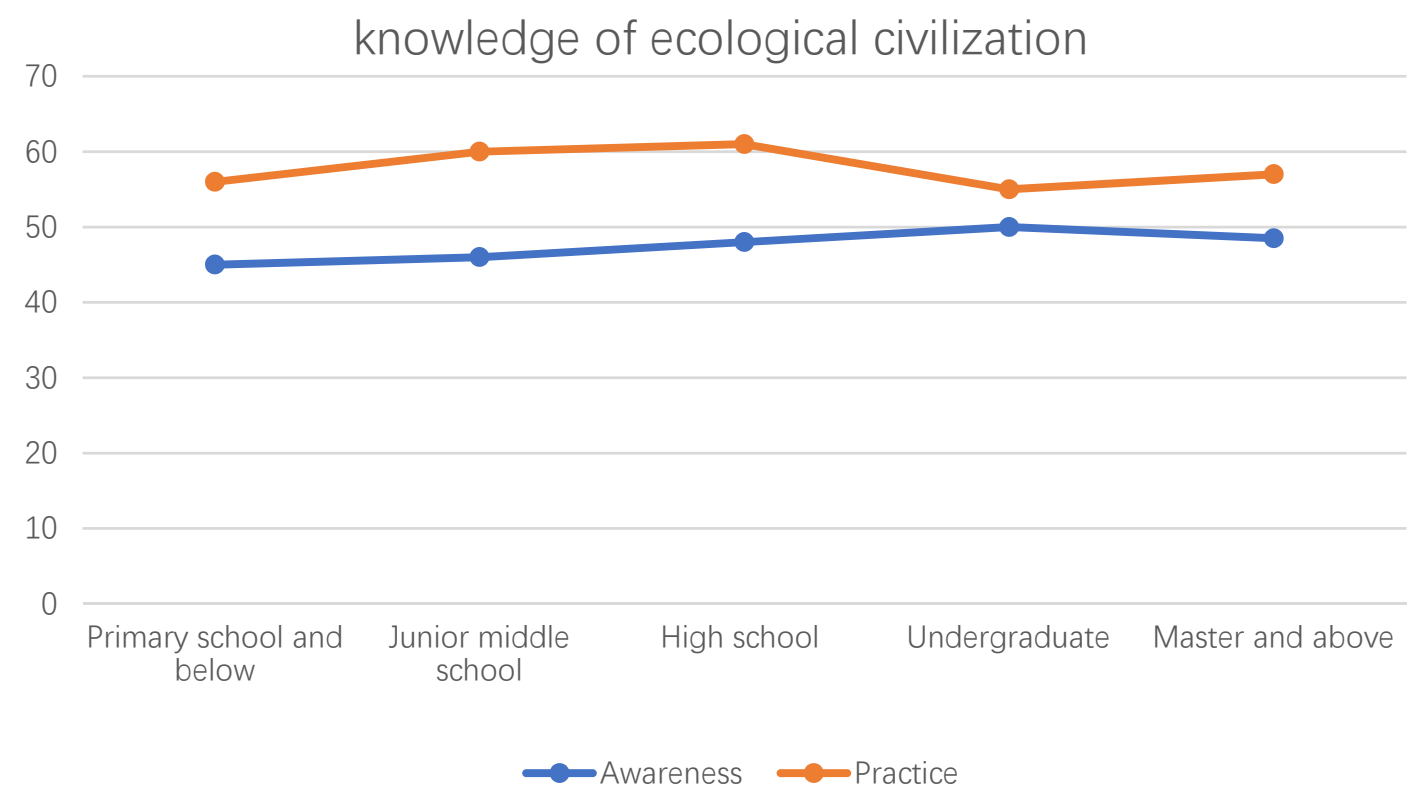

Figure 2 Range of respondents' knowledge of ecological civilization Source from: Report on the investigation of ecological civilization consciousness in China

Although students have learned the concept about environmental protection and sustainable development in class, it is still lack of in-depth understanding of the requirements and systems of ecological civilization. Second, the ability of college students to transform environmental protection concept is weak, which is inconsistent with their ecological responsibility. For example, the use of plastic products, garbage sorting and so on. Finally, Universities strive to build various forms of ecological civilization education because of the national attention on them. Therefore, college students need to apply the concept of environmental protection and ecological civilization to their study and life, for future construction of green and healthy environment.

\section{Means of Integrating Environmental Protection Concept into Ideological and Political Education}

\subsection{Improve the practical ability to solve ecological problems}

It is an important direction of ecological civilization education to cultivate college students' thinking ability and practical ability to deal with ecological problems in real life. To achieve this goal, first of all, universities need to enhance the sense of responsibility of college Ideological and Political teachers, ensure the teachers' sense on ecological civilization education, and understand the social mission of education, which can better achieve the educational effect. In addition, teachers should also guide college students to constantly find problems and put forward problems on the basis of the theory of Ideological and political course, so as to deepen the theoretical significance in practice, such as the ecological protection of the environment around the school, the current situation of the environment in the city, ect... [4].

\subsection{Develop rich and colorful practical activities}

The traditional form of environmental protection education has not played an effective role. Universities should integrate education with ecological and environmental protection behavior and fully mobilize college students' participation and enthusiasm in environmental protection education of Ideological and political education [4]. College students will have a sense of internal identity on environmental protection and ecology through their participation of practical activities. And it can finally increase students' green environmental protection responsibility given by the society. 


\section{Ways to obtain ecological civilization information}

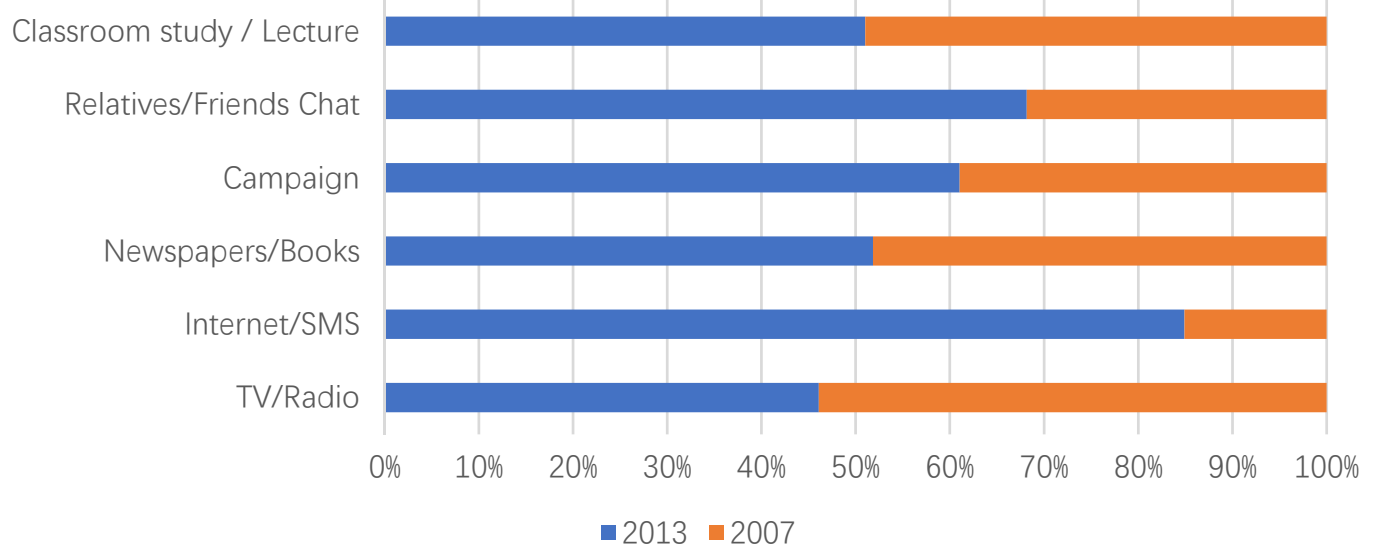

Figure 3 Comparison of the main ways to obtain ecological civilization information

Source from: Report on the investigation of ecological civilization consciousness in China

According to the changes of information dissemination channels and forms and public access to information channels, universities should adjust the content and forms of publicity, so as to achieve targeted and accurate communication. Giving full play to the platform of digital new media, universities should actively explore the methods and strategies of using new media for environmental information dissemination, public complaint feedback, online interactive communication, environmental public opinion monitoring and environmental emergency response. This requires universities strengthen cooperation with telecom, new media and other channel providers and content producers, strengthen publicity, communication, investigation and interaction through mobile Internet, mobile terminals, environmental protection microblog, WeChat and app, and improve the transparency, timeliness and quickness of information. In this way, they can make the ecological civilization propaganda report closer to students, and improve their communication ability and interactivity of ecological civilization information.

\section{The combination of environmental protection concept and ideological and political education}

Theory is the guide of action. With the innovation of network information technology, the development innovation path of education is regulated and selected by technology. Under the data analysis, the integration of intelligent drive and ideological and political course is an inevitable development trend. University educators should understand the basic principle of intelligent drive system and its integration with ideological and political course [5].
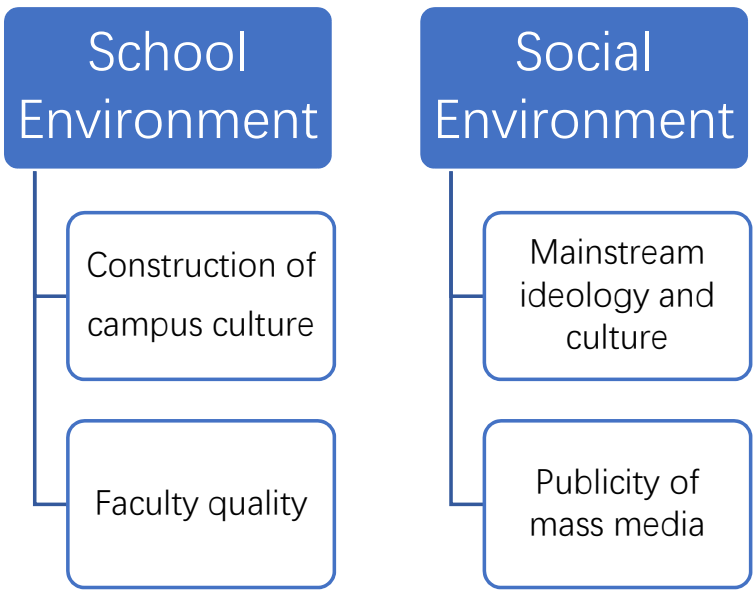

Figure 4 Environmental impact of Ideological and political education

The education of ecological consciousness should run through the ideological and political curriculum system. Flexible use of case teaching, on-site discussion, online plus offline combination of teaching mode, guide college students to combine classroom knowledge with real environmental problems. Besides, through the development of practical education activities, universities should encourage college students go to nature for stimulating the awareness of protecting the natural environment. In the ideological and political course, 
universities can design theme class meetings, organize academic discussion and exchange opinions on environmental issues, regularly organize excellent evaluation activities, supplemented by material or spiritual rewards for college students to increase their environmental protection awareness. In addition, they should actively organize environmental protection series lectures, knowledge competitions, social inspection and other educational activities [6]. To create a campus ecological and cultural atmosphere and enhance the real emotional experience of college students are also the most effective way of education. Universities can arouse the ecological protection consciousness and behavior of college students from the campus hardware construction, including system design and other aspects of reasonable design.

\section{Conclusion}

In conclusion, in the process of cultivating ideological and moral quality, the integration of environmental protection concept and ecological civilization construction concept is the key to help college students form the concept of environmental protection and ecology. In order to promote the sustainable development of society as a whole, universities should integrate the contents of environmental protection and sustainable development into the curriculum practice, focusing on Ideological and political education. At the same time, universities should cultivate comprehensive talents who love environmental protection in the new era.

\section{ACKNOWLEDGEMENT}

This work was supported by the project researching the theory and practice of Ideological and Political Education of college students in Guangxi in 2020: Study on the reform and practice of "Wisdom" Ideological and Political Course in western universities in the new era (2020SZ045).

\section{Reference}

1. Li Na, Hu Xuexia, Jia Fang, "Environmental NGOs and ideological and political education in Colleges and universities", Journal of Henan Normal University: Philosophy and Social Sciences, 2016, pp.173-177.

2. Li Yun, "Research on integration and combination of environmental protection concept in Ideological and political education in Colleges and universities", Environmental science and management, 2018, pp.27-31.

3. Zhang Guiju. "Research on the integration and innovation of environmental protection concept in University Ideological and Political Education “. China's off campus education, 2019, pp.83-84.

4. Hu Keren. Analysis of the current situation and problems of ecological civilization education for college students. Chinese and foreign entrepreneurs, 2017.

5. Zhang Pingquan. "Content structure and expression of integrating ecological civilization literacy education into Ideological and political education in Colleges and universities.", Journal of Heilongjiang Institute of education, 2016, PP: 51-53.

6. Wang Jinying, Quan Li. Research on ecological consciousness education of college students in China. Journal of Baoji University of Arts and Sciences: Social Science Edition, 2016, pp.115. 